\title{
Effect of Azospirillum brasilense and Methylobacterium oryzae Inoculation on Growth of Red Pepper (Capsicum annuum L.)
}

\author{
Jong-Bae Chung* and Tong-Min $\mathrm{Sa}^{1}$ \\ Division of Life and Environmental Science, Daegu University, Gyeongsan 712-714, Korea \\ ${ }^{1}$ Department of Agricultural Chemistry, Chungbuk National University, Cheongju 361-763, Korea
}

\begin{abstract}
Plant growth-promoting effects of rhizobacterial inoculation obtained in pot experiments cannot always be dependably reproduced in fields. In this study, we investigated the effect of inoculation with Azospirillum brasilense and Methylobacterium oryzae, which have displayed growth promoting effects in several pot experiments, on growth and fruit yield of red pepper under field condition in a plastic-film house. Four rows spaced $90 \mathrm{~cm}$ apart were prepared after application of compost $\left(10 \mathrm{Mg} \mathrm{ha}^{-1}\right)$, and red pepper seedlings (Capsicum annum L., Nocgwang) were transplanted in each row with 40-cm space. Experimental treatments were consisted of $A$. brasilense CW903 inoculation, M. oryzae CBMB20 inoculation, and uninoculated control. Twelve plots, 10 plants per plot, were allotted to the three treatments with four replicates in a completely randomized design. At the time of transplanting, $50 \mathrm{~mL}$ of each inoculum $\left(1 \times 10^{8}\right.$ cells $\left.\mathrm{mL}^{-1}\right)$ was introduced into root zone soil of each plant, and re-inoculated at 7 and 14 days after transplant. Plant growth and fruit yield were measured during the experiment. Both $A$. brasilense CW903 and M. oryzae CBMB20 could not promote growth of red pepper plants. All growth parameters measured were not significantly different among treatments. There were large variations in fruit yield recorded on plot basis, and no statistically significant differences were found among treatments. The failure to demonstrate the expected plant growth promoting effect of the inoculants is possibly due to various environmental factors, including weather and soil characteristics, reducing the possibility to express the potential of the inoculated bacterial strains.
\end{abstract}

Key words: Azospirillum brasilense, Methylobacterium oryzae, Plant growth promotion, Red pepper

\section{Introduction}

Plant growth in agricultural soils is influenced by various biotic and abiotic factors. Microorganisms that colonize the rhizosphere exert beneficial effects ranging from direct influence mechanisms to an indirect effect on plant growth. Thus, soil bacteria that inhabit plant roots and benefit plants by providing growth promotion are termed plant growth-promoting rhizobacteria (Bashan and Holguin 1997). Various rhizobacteria were reported to have many plant growth promoting abilities including $\mathrm{N}$ fixation, $\mathrm{P}$ solublization, production of plant growth hormones, GAs, cytokinins and auxins, and biological disease control (Madhaiyan et al., 2004, 2006a, 2007, 2009; Omer et al., 2004; Ryu et al., 2006).

Various species of bacteria including Azotobacter, Azospirillum, Bacillus, Pseudomonas, Rhizobium, and

\footnotetext{
Received : January 12. 2012 Accepted : February 7. 2012

*Corresponding author : Phone: +82538506755

E-mail: jbchung@daegu.ac.kr
}

Methylobacterium have been isolated and characterized in terms of their plant growth promotion abilities (Dobbelaere et al., 2002; Gray and Smith, 2005; Nautiyal et al., 2006; Poonguzhali et al., 2008; Ryu et al., 2006). While appropriate application of chemical fertilizers is essential in modern farming systems, deleterious environmental impacts of fertilization should be minimized. Using plant growth promoting microbes, possessing the versatile plant-beneficial traits, fertilizer application can be reduced (Adesemoye et al., 2008; Ahemad and Khan, 2011; Dobbelaere et al., 2002; Kloepper et al., 2004; Madhaiyan et al., 2004, 2009, 2010; Vessey, 2003; Weller, 2007). Various bacterial species have been successfully used in inoculation trials in pot experiments under greenhouse condition (Bashan and Holguin, 1997; Masheshawari, 2011). However, commercial application of plant growth promoting microbes on a large scale is still very limited, and the main obstacle is the unpredictability and inconsistency of field results (Bashan and Holguin, 1997). 
Recently we isolated bacterial species of Methylobacterium and Azospirillum from rice and taro, respectively, and their plant growth promoting abilities were confirmed in laboratory and greenhouse experiments (Chauhan et al., 2010; Kim et al., 2005; Madhaiyan et al., 2004, 2007, 2010; Ryu et al., 2006). Methylobacterium spp. are a group of bacteria known as pink pigmented facultative methylotrophs (Austin and Goodfellow, 1979), and they were reported to distribute ubiquitously in the plant phyllosphere and rhizosphere (Corpe and Basile, 1982). Methylobacterium improves plant growth through the production of the enzyme urease or phytohormone IAA and cytokinins, lowering ethylene levels in plants, production of siderophores and protection against pathogens (Idris et al., 2004; Madhaiyan et al., 2004, 2006a, 2006b; Omer et al., 2004). Azospirillum brasilense is a well studied bacterium found in the rhizosphere of various crop plants originally defined as a nitrogen fixer but later known for its production of the plant growth hormone IAA (Bashan and Holguin, 1997; Bashan et al., 2004; Okon et al., 1995). However, most of these informations correspond to experiments performed under controlled conditions.

Therefore, before applications in a large scale of real farming systems, it is necessary to confirm the reproducibility of plant growth-promoting potential of rhizobacteria in field conditions. And much more information is needed to explain the success or failure in plant growth and yield response upon bacterial inoculation. In this study, we investigated the effect of rhizosphere inoculation with $A$. brasilense and $M$. oryzae, which have displayed growth promoting effects in several pot experiments, on the growth and fruit yield of red pepper plant under a reduced fertilization level in the field of plastic-film house.

\section{Materials and Methods}

Bacterial strains and inoculum culture Methylobacterium oryzae CBMB20 (Madhaiyan et al., 2006a,
2007) and Azospirillum brasilense CW903 (Kim et al., 2005) were used in this study. The strains were cultured in ammonium mineral salts minimal broth with $0.5 \%$ methanol for 4 days (M. oryzae CBMB20), and in nitrogen free malic acid broth supplemented with $1 \mathrm{~g} \mathrm{NH}_{4} \mathrm{Cl}$ per liter for $48 \mathrm{~h}$ (A. brasilense CW903) at $30^{\circ} \mathrm{C}$ under shaking.

Plant culture with bacterial inoculation Plant growth experiment was conducted in a plastic-film house at Experimental Farm of Daegu University. Characteristics of the house soil are shown in Table 1. The experimental field plots were prepared after application of compost $\left(10 \mathrm{Mg} \mathrm{ha}^{-1}\right)$ two weeks before transplanting of red pepper seedlings. Four rows spaced $90 \mathrm{~cm}$ apart were prepared in the plastic-film house $(6.5 \mathrm{~m} \times 35 \mathrm{~m})$. Thirty five-day-old red pepper seedlings (Capsicum annum L., Nocgwang) from a commercial nursery were transplanted on May 4, 2011 in each raw with $40-\mathrm{cm}$ space.

Treatments of $M$. oryzae CBMB20 inoculation, $A$. brasilense CW903 inoculation, and uninoculated control were included in the experiment. Twelve plots, 10 plants in each plot, were allotted to the three treatments with four replicates in a completely randomized design. At the time of transplanting, $50 \mathrm{~mL}$ of inoculum $\left(1 \times 10^{8}\right.$ cells $\mathrm{mL}^{-1}$ ) was introduced into the root zone soil of each red pepper plant, and plants were re-inoculated at 7 and 14 days after transplant. The inoculum was applied on the soil surface and enough water was applied to facilitate the flow of bacterial inoculum down to the root zone soil.

Plant height, number of leaves or stems, and length of the largest leaf were recorded at 20,40, 50,60, and 70 days after transplant. Fruits larger than $8 \mathrm{~cm}$ were harvested at $40,50,60,70$, and 80 days after transplant, and total number and fresh weight of the fruits were recorded. Four plants were collected in each plot at 80 days after transplant, and fresh weights of shoot and root were recorded.

Table 1. Some physicochemical characteristics of the soil used in experiment.

\begin{tabular}{|c|c|c|c|c|c|c|c|c|c|}
\hline \multirow{2}{*}{$\mathrm{pH}$} & \multirow{2}{*}{$\mathrm{EC}_{\mathrm{e}}$} & \multirow{2}{*}{$\begin{array}{c}\text { Organic } \\
\text { matter }\end{array}$} & \multirow{2}{*}{ Total N } & \multirow{2}{*}{ Avail. $\mathrm{P}_{2} \mathrm{O}_{5}$} & \multicolumn{3}{|c|}{ Exch. Cation } & \multirow{2}{*}{ CEC } & \multirow{2}{*}{ Texture } \\
\hline & & & & & $\mathrm{Ca}$ & $\mathrm{Mg}$ & $\mathrm{K}$ & & \\
\hline$(1: 5)$ & $\mathrm{dS} \mathrm{m}^{-1}$ & $\mathrm{~g} \mathrm{~kg}^{-1}$ & $\mathrm{~g} \mathrm{~kg}^{-1}$ & $\mathrm{mg} \mathrm{kg}{ }^{-1}$ & ----- & $-\mathrm{cr}$ & $\mathrm{g}^{-1}-$ & ------- & \\
\hline 6.7 & 3.2 & 26 & 1.7 & 390 & 5.8 & 2.6 & 1.4 & 11.5 & Sandy clay \\
\hline
\end{tabular}


Statistical analyses Significant differences among the treatments were calculated by Duncan's multiple range tests using SigmaStat version 2.0 (Systat Software, San Jose, CA).

\section{Results and Discussion}

Although plant growth promoting abilities of Methylobacterium and Azospirillum strains were found in several laboratory and pot experiments, these plant responses upon the rhizobacterial inoculation should be confirmed under field conditions before large-scale commercial applications. The effects of $A$. brasilense CW903 and M. oryzae CBMB20 on growth of red pepper plants were investigated in a plastic-film house culture experiment.

Growth parameters measured five times during the experiment are presented in Table 2. Both strains of A. brasilense CW903 and M. oryzae CBMB20 could not promote growth of red pepper plant. All growth parameters measured were not significantly different among the treatments. At 80 days after transplant, mean fresh biomass of red pepper plants treated with A. brasilense CW903 or M. oryzae CBMB20 was not significantly different compared to the biomass observed in non-inoculated control plants (Table 3). And plant growth promoting effects of the two bacterial strains were also not significantly different. Fruit yield of

Table 2. Effect of inoculation of Azospirillum brasilense CW903 and Methylobacterium oryzae CBMB20 on red pepper plant growth. Values (mean $\pm \mathrm{SE}$ ) in the same column of each measuring date followed by the same letter are not significantly different at $P=0.05$ (Duncan's multiple range test).

\begin{tabular}{|c|c|c|c|c|c|}
\hline Date & Treatment & Plant height & Number of leaves & Number of stems & $\begin{array}{l}\text { Length of the } \\
\text { largest leaf }\end{array}$ \\
\hline & & $\mathrm{cm}$ & & & $\mathrm{cm}$ \\
\hline \multirow{3}{*}{20 DAT } & Control & $39.5 \pm 1.85 \mathrm{a}$ & $30.9 \pm 4.15 a$ & - & $7.7 \pm 0.42 \mathrm{a}$ \\
\hline & A. brasilense & $40.2 \pm 0.81 \mathrm{a}$ & $30.5 \pm 2.51 \mathrm{a}$ & - & $7.8 \pm 0.49 a$ \\
\hline & M. oryzae & $40.2 \pm 3.51 \mathrm{a}$ & $29.5 \pm 3.45 \mathrm{a}$ & - & $7.8 \pm 0.68 \mathrm{a}$ \\
\hline \multirow{3}{*}{40 DAT } & Control & $75.8 \pm 3.09 a$ & - & $82.2 \pm 10.0 \mathrm{a}$ & $12.5 \pm 0.73 \mathrm{a}$ \\
\hline & A. brasilense & $76.5 \pm 1.93 a$ & - & $82.5 \pm 10.3 \mathrm{a}$ & $11.8 \pm 0.39 a$ \\
\hline & M. oryzae & $77.4 \pm 2.52 \mathrm{a}$ & - & $91.8 \pm 7.75 \mathrm{a}$ & $12.8 \pm 0.62 \mathrm{a}$ \\
\hline \multirow{3}{*}{$50 \mathrm{DAT}$} & Control & $84.9 \pm 4.69 a$ & - & $102.2 \pm 22.9 \mathrm{a}$ & $13.8 \pm 0.84 \mathrm{a}$ \\
\hline & A. brasilense & $81.1 \pm 1.60 \mathrm{a}$ & - & $83.9 \pm 10.5 \mathrm{a}$ & $12.3 \pm 0.33 \mathrm{a}$ \\
\hline & M. oryzae & $82.3 \pm 2.64 a$ & - & $99.0 \pm 12.9 \mathrm{a}$ & $12.8 \pm 0.62 \mathrm{a}$ \\
\hline \multirow{3}{*}{60 DAT } & Control & $104.5 \pm 4.51 \mathrm{a}$ & - & $139.8 \pm 4.67 \mathrm{a}$ & $13.6 \pm 0.44 a$ \\
\hline & A. brasilense & $102.0 \pm 1.29 \mathrm{a}$ & - & $140.1 \pm 10.3 \mathrm{a}$ & $12.9 \pm 0.33 \mathrm{a}$ \\
\hline & M. oryzae & $102.9 \pm 3.64 \mathrm{a}$ & - & $137.6 \pm 2.87 \mathrm{a}$ & $13.2 \pm 0.29 \mathrm{a}$ \\
\hline \multirow{3}{*}{70 DAT } & Control & $122.4 \pm 2.95 \mathrm{a}$ & - & $133.3 \pm 10.7 \mathrm{a}$ & $14.2 \pm 0.49 \mathrm{a}$ \\
\hline & A. brasilense & $118.4 \pm 1.56 \mathrm{a}$ & - & $120.4 \pm 2.58 \mathrm{a}$ & $13.2 \pm 0.33 \mathrm{a}$ \\
\hline & M. oryzae & $120.4 \pm 3.40 \mathrm{a}$ & - & $133.7 \pm 7.72 \mathrm{a}$ & $13.8 \pm 0.52 \mathrm{a}$ \\
\hline
\end{tabular}

Table 3. Effect of inoculation of Azospirillum brasilense CW903 and Methylobacterium oryzae CBMB20 on the biomass of red pepper plant. Four red pepper plants were collected in each plot at 80 days after transplant, and fresh weights of shoot and root were recorded. Values (mean $\pm \mathrm{SE}$ ) in the same column followed by the same letter are not significantly different at $P=0.05$ (Duncan's multiple range test).

\begin{tabular}{ccc}
\hline \hline Treatment & Shoot & Root \\
\hline & g plant $^{-1}$ & g plant $^{-1}$ \\
Control & $479.8 \pm 61.28 \mathrm{a}$ & $47.3 \pm 4.99 \mathrm{a}$ \\
A. brasilense CW903 & $466.5 \pm 76.15 \mathrm{a}$ & $47.8 \pm 4.79 \mathrm{a}$ \\
M. oryzae CBMB20 & $480.5 \pm 91.26 \mathrm{a}$ & $48.0 \pm 5.89 \mathrm{a}$ \\
\hline LSD $_{0.05}$ & 123.5 & 8.4 \\
\hline
\end{tabular}


red pepper plant was estimated by measuring total number and fresh weight of the fruits ( $>8 \mathrm{~cm}$ long) harvested in each plot 5 times from 40 to 80 days after transplant (Table 4). There were large variations in total number and fresh weight of fruits harvested and measured on plot basis, and any statistically significant differences were not found among treatments. These results indicate that the positive plant growthpromoting potential of the inoculants expressed in pot experiments cannot always be reproduced under field conditions.

As demonstrated in numerous worldwide trials, we have already found positive effects of $A$. brasilense CW903 and M. oryzae CBMB20 inoculation on plant growth in the previous laboratory and pot experiments with wheat, rice, red pepper, tomato, canola, and groundnut (Madhaiyan et al., 2004; Madhaiyan et al., 2006a; Madhaiyan et al., 2006b; Madhaiyan et al., 2007; Madhaiyan et al., 2010; Ryu et al., 2006). Plant growth promoting effect of $A$. brasilense could be attributed to several mechanisms including enhancement of root development, production of growth regulators and nitrogen fixation (Bashan and Holguin, 1997; Kim et al., 2005). Methylobacterium oryzae can produce phytohormones like cytokinins and auxins (Madhaiyan et al., 2005), fix atmospheric N (Jourand et al., 2004; Raja et al., 2006), regulate the ethylene level in rhizosphere by producing the enzyme ACC deaminase (Chinnadurai et al., 2009; Madhaiyan et al., 2006a), and stimulate resistance against pathogens (Madhaiyan et al., 2006b).

Most of this information corresponds to experiments performed using small number of plants grown in pots under controlled conditions. Although the positive responses of crop plants to inoculation of $A$. brasilense CW903 and M. oryzae CBMB20 were clearly demons- trated under controlled conditions (Kim et al., 2011; Madhaiyan et al., 2010; Ryu et al., 2006), in this study conducted under field condition, inoculations of A. brasilense CW903 and M. oryzae CBMB20 were not effective on promotion of the growth and fruit yield of red pepper plant. Bashan et al. (2004) suggested that the good positive plant growth-promoting effects obtained under pot experiments cannot always be dependably reproduced under field conditions. Recently, Naiman et al. (2009) also reported that inoculation of wheat with $A$. brasilense and $P$. fluorescens could not significantly increase the aerial biomass production and grain yield in a field experiment. This inconsistency restricts further development of plant growth promoting rhizobacteria as a commercial inoculum on large scale crop cultivations (Bashan and Holguin, 1997; Maheshwari, 2011). However, the factors or conditions responsible for the inconsistent performance of plant growth promoting rhizobacteria in pot and field trials have not yet been clearly identified.

In this study, we did not investigate the ecological and environmental factors that determine the survival and activity of inoculated rhizobacteria in the plant rhizosphere. The failure to demonstrate the expected plant growth-promoting effects of bacterial inoculants under field condition is possibly due to the considerable competition between native and added bacteria which reducing the possibility to express the potential of the inoculated strains. Also the variability in the performance of plant growth promoting rhizobacteria is possibly due to the various environmental factors, including weather and soil characteristics, which may affect their growth and effects on plant. Generally, the most pronounced effect of inoculation is observed at low to intermediate soil fertility levels (Dobbelaere et al., 2002; Saubidet et al., 2002; Tien et al., 1979;

Table 4. Comparison of fruit yield of red pepper plants inoculated with A. brasilense CW903 and M. oryzae CBMB20. At 40, 50, 60, 70, and 80 days after transplant, fruits larger than $8 \mathrm{~cm}$ were harvested and total number and fresh weight of the fruits were recorded. Values (mean $\pm \mathrm{SE}$ ) in the same column followed by the same letter are not significantly different at $P=0.05$ (Duncan's multiple range test).

\begin{tabular}{ccc}
\hline \hline Treatment & Number of fruit & Weight of fruit \\
\hline & ea $\operatorname{plot}^{-1}$ & plot $^{-1}$ \\
Control & $337 \pm 61 \mathrm{a}$ & $2788 \pm 737 \mathrm{a}$ \\
A. brasilense CW903 & $318 \pm 87 \mathrm{a}$ & $2670 \pm 1165 \mathrm{a}$ \\
M. oryzae CBMB20 & $351 \pm 83 \mathrm{a}$ & $2823 \pm 1108 \mathrm{a}$ \\
\hline LSD $_{0.05}$ & 124.2 & 1633.3 \\
\hline
\end{tabular}


Zimmer and Bothe, 1988).

With inoculation of growth-promoting rhizobacteria, the rapid establishment of root system by increasing root branching, root length, and/or the amount of root hairs, and this is advantageous for young seedlings in obtaining water and nutrients from their environment, thereby enhancing their chances for survival and growth (Ryu et al., 2006). This probably could be a reason for the more pronounced growth-promoting effect of bacterial inoculation at the early growth stages of plants (Dobbelaere et al., 2002; Madhaiyan et al., 2010; Tien et al., 1979). However, in this study root biomass measured at 80 days after transplant was not significantly different among the treatments (Table 3), and the shoot growth and fruit yield of red pepper not affected by the inoculation could be associated with this negative effect of inoculation on root growth. It is known that a rapid development of root system with bacterial inoculation would not always be associated with the growth or yield of plants in relatively fertile soils (Bashan and Holguin, 1997). In this study, red pepper plant was grown in the plastic-film house previously used in potato cultivation with sole application of commercial compost at the rate of $10 \mathrm{Mg} \mathrm{ha}^{-1}$. Since the red pepper plants in control plots did not show any specific nutrient deficiencies, soil fertility was probably not quite below the optimal level for red pepper. Therefore, the beneficial effects of bacterial inoculations for red pepper plants in utilization of nutrients may not be expected, and this is probably associated with the no significant growth-promoting effects of the inoculations with A. brasilense CW903 and $M$. oryzae CBMB20 found in this experiment.

Nitrogen fixation is another important mechanism proposed to explain the promotion of plant growth by N-fixing rhizobacteria including Azospirillum spp.; regularly the contribution is smaller than 5\% (Bashan and Holguin, 1997). Saubidet et al. (2002) reported that the increase of $\mathrm{NO}_{3}{ }^{-}$observed in wheat plants inoculated with Azospirillum spp. could not be explained by $\mathrm{N}$ fixation, and only by $\mathrm{NO}_{3}{ }^{-}$uptake from the soil. The bacterial strains A. brasilense CW903 and $M$. oryzae CBMB20 used in this experiment are known to have the ability to fix atmospheric N, but it is still not clearly displayed how much $\mathrm{N}$ can be supplied to the host plants by the bacterial $\mathrm{N}$ fixation. And the beneficial effect of $\mathrm{N}$-fixation with inoculation of plant growth-promoting rhizobacteria also could be negligible for plants grown in relatively fertile soils.

Yet, there is no definite agreement on exactly how the bacteria can effect plant growth, and other factors responsible for the failure in plant growth stimulation with bacterial inoculation under field conditions cannot be further discussed here. One of the challenges of using plant growth-promoting rhizobacteria is obviously natural variation. Although the possibility to express the plant growth-promoting potential of rhizobacteria would be considerably restricted under relatively well managed growth environments, it is difficult to predict how an organism may respond when placed in the field. For commercial utilization of plant growth-promoting rhizobacteria as the potential tools for sustainable agriculture, various parameters critical in displaying the growth or yield promotion ability of the beneficial bacterial inoculants should be further investigated.

\section{Conclusion}

Various mechanisms through which the plant growthpromoting rhizobacteria affect the plant have been proposed, and growth-promoting effects of various bacterial strains were confirmed from many laboratory and pot trials. However, it is true that the positive effects of bacterial inoculations obtained under controlled environments cannot always be dependably reproduced under field conditions. Some parameters, such as the number of bacterial cells and the inoculation method, have been proposed to be critical for successful inoculation. But the factors or conditions responsible for the success or failure in plant growth and yield response upon inoculation have not yet been clearly identified. For better understanding of the basic features of the bacteria-root interaction and the parameters critical to obtain successful inoculation should be further investigated before large-scale field application with reliable efficacy.

\section{Acknowledgement}

This study was carried out with the support of "Cooperative Research Program for Agricultural Science \& Technology Development (Project No. PJ007880)", Rural Development Administration, Republic of Korea. 


\section{References}

Adesemoye, A.O., H.A. Torbert, and J.W. Kloepper. 2008. Enhanced plant nutrient use efficiency with PGPR and AMF in an integrated nutrient management system. Can. J. Microbiol. 54:876-886.

Ahemad, M. and M.S. Khan. 2011. Functional aspects of plant growth promoting rhizobacteria: recent advancements. Insight Microbiol. 1:39-54.

Aloni, R., E. Aloni, M. Langhans, and I. Ullrich. 2006. Role of cytokinin and auxin in shaping root architecture: regulating vascular differentiation, lateral root initiation, root apical dominance and root gravitropism. Ann. Bot. 97:883-893.

Austin, B. and M. Goodfellow. 1979. Pseudomonas mesophilica, a new species of pink bacteria isolated from leaf surfaces. Int. J. Syst. Bacteriol.29:373.

Bashan, Y. and G. Holguin. 1997. Azospirillum-plant relationships: environmental and physiological advances (1990-1996). Can. J. Microbiol. 43:103-121.

Bashan, Y., G. Holguin, and L.E. de Bashan. 2004. Azospirillumplant relationships: physiological, molecular, agricultural, and environmental advances (1997-2003). Can. J. Microbiol. 50: 521-577.

Chinnadurai, C., D. Balachandar, and S.P. Sundaram. 2009. Characterization of 1-aminocyclopropane-1-carboxylate deaminase producing methylobacteria from phyllosphere of rice and their role in ethylene regulation. World J. Microbiol. Biotechnol. 25:1403-1411.

Chauhan, P.S., G.S. Lee, M.K. Lee, W.J. Yim, G.J. Lee, Y.S. Kim, J.B. Chung, and T.M. Sa. 2010. Effect of inoculation of Methylobacterium oryzae on the growth of red pepper at different organic fertilizer levels. Korean J. Soil Sci. Fert. 43:506-513.

Corpe, W.A. and D.V. Basile. 1982. Methanol utilizing bacteria associated with green plants. Dev. Indust. Microbiol. 23:483493

Dobbelaere, S., A. Croonenborghs, A. Thys, D. Ptacek, Y. Okon, and J. Vanderleyden. 2002. Effect of inoculation with wild type Azospirillum brasilense and A. irakense strains on development and nitrogen uptake of spring wheat and grain maize. Biol. Fertil. Soils 36:28-297.

Gray, E.J. and D.L. Smith. 2005. Intracellular and extracellular PRPR: commonalities and distinctions in the plant-bacterium signaling processes. Soil Biol. Biochem. 37:395-412.

Idris, R., R. Trifonova, M. Puschenreiter, W.W. Wenzel, and A. Sessitsch. 2004. Bacteial communities associated with flowering plants of the Ni hyperaccumulator Thlaspi goesingense. Appl. Environ. Microbiol. 70:2667-2677.

Jourand, P., E. Giraud, G. Bena, A. Sy, A. Willems, M. Gillis, B. Dreyfus, and P. de Lajudie. 2004. Methylobacterium nodulans sp. nov., for a group of aerobic, facultatively methylotrophic, legume root nodule-forming and nitrogen-fixing bacteria. Int. J. Syst. Evol. Microbiol. 54:2269-2273.

Kim, C.W., M.L. Kecskes, R.J. Deaker, K. Gilchrist, P.B. New, I.R. Kennedy, S.H. Kim, and T.M. Sa. 2005. Wheat root colonization and nitrogenase activity by Azospirillum isolates from crop plants in Korea. Can. J. Microbiol. 51:948-956.

Kim, B.H., T.M. Sa, and J.B. Chung. 2011. Effect of inoculation of Azospirillum brasilense and Methylobacterium oryzae on the growth of red pepper plant. Korean J. Environ. Agric. 30:223-228.

Kloepper, J.W., C.M. Ryu, and S. Zhang. 2004. Induced systemic resistance and promotion of plant growth by Bacillus spp. Phytopathol. 94:1259-1266.

Madhaiyan, M., S. Poonguzhali, M. Senthilkumar, S. Seshadri, H.K. Chung, J.C. Yang, S.P. Sundaram, T.M. Sa. 2004. Growth promotion and induction of systemic resistance in rice cultivar Co-47 (Oryza sativa L.) by Methylobacterium spp. Bot. Bull. Acad. Sin. 45:315-324.

Madhaiyan, M., S. Poonguzhali, J.H. Ryu, and T.M. Sa. 2006 a. Regulation of ethylene levels in canola (Brassica campestris) by 1-aminocyclopropane-1-carboxylate deaminase containing Methylobacterium fujisawaense. Planta 224:268-278.

Madhaiyan M, B.V.S. Reddy, R. Anandam, M. Senthilkumar, S. Poonguzhali, S.P. Sundaram, and T.M. Sa. 2006b. Plant growth-promoting Methylobacterium induces defense responses in ground nut (Arachis hypogaea L.) compared with rot pathogen. Curr. Microbiol. 53:270-276.

Madhaiyan, M., B.Y. Kim, S. Poonguzhali, S.W. Kwon, M.H. Song, J.H. Ryu, S.J. Go, B.S. Koo, and T.M. Sa. 2007. Methylobacterium oryzae sp. nov., a novel aerobic, pinkpigmented, facultatively methylotrophic, 1-aminocyclopropane1-carboxylate deaminase producing bacterium isolated from rice. Int. J. Syst. Evol. Microbiol. 57:326-331.

Madhaiyan, M., S. Poonguzhali, M. Senthilkumar, S. Sundaram, and T.M. Sa. 2009. Nodulation and plant-growth promotion by methylotrophic bacteria isolated from tropical legumes. Microbiol. Res. 164:114-120.

Madhaiyan, M., S. Poonguzhali, B.G. Kang, Y.J. Lee, J.B. Chung, and T.M. Sa. 2010. Effect of co-inoculation of methylotrophic Methylobacterium oryzae with Azospirillum brasilense and Burkholderia pyrrocinia on the growth and nutrient uptake of tomato, red pepper and rice. Plant Soil 328:71-82.

Masheshawari, D.K. 2011. Bacteria in agrobiology: Plant growth responses. Springer, New York, USA.

Naiman, A.D., A. Latronico, and E.G. Garcia de Salamone. 2009. Inoculation of wheat with Azospirillum brasilense and Pseudomonas fluorescens: Impact on the production and culturable rhizosphere microflora. Eur. J. Soil Biol. 45:44-51.

Nautiyal, C.S., S. Mehta, and H.B. Singh. 2006. Biological control and plant growth-promotion by Bacillus strains from milk. J. Microbiol. Biotechnol. 16:184-192.

Okon, Y., R. Itzigsohn, S. Burdman, and M. Hampel. 1995. Advances in agronomy and ecology of the Azospirillum/plant association. p. 635-640. In I.A. Tikhonovich et al. (ed.) Nitrogen fixation: fundamentals and applications. Kluwer Academic, Dordrecht, The Netherlands.

Omer, Z.S., R. Tombolini, A. Broberg, and B. Gerhardson. 2004. Indole-3-acetic acid production by pink-pigmented facultative methylotrophic bacteria. Plant Growth Regul. 43:93-96.

Poonguzhali, S., M. Madhaiyan, and T. Sa. 2008. Isolation and 
identification of phosphate solubilizing bacteria from Chinese cabbage and their effect on growth and phosphorus utilization of plants. J. Microbiol. Biotechnol. 18:773-777.

Raja, P, S. Uma and S.P. Sundaram. 2006. Non-nodulating pinkpigmented facultative Methylobacterium sp. with a functional nifH gene. World J. Microbiol. Biotechnol. 22:1381-1384.

Ryu, J.H., M. Madhaiyan, S. Poonguzhali, W.J. Yim, P. Indiragandhi, K.A. Kim, R. Anandham, J.C. Yun, and T.M. Sa. 2006. Plant growth substances produced by Methylobacterium spp. and their effect on tomato (Lycopersicon esculentum L.) and red pepper (Capsicum annuum L.) growth. J. Microbiol. Biotechnol. 16:1622-1628.

Saubidet, M.I., N. Fatta, and A.J. Barneix. 2002. The effect of inoculation with Azospirillum brasilense on growth and nitrogen utilization by wheat plants. Plant Soil 245:215-222.

Tien, T.M., M.H. Gaskins, and D.H. Hubbell. 1979. Plant growth substances produced by Azospirillum brasiense and their effect on the growth of pearl millet (Pennisetum americanum L.). Appl. Environ. Microbiol. 37:1016-1024.

Vessey, J.K. 2003. Plant growth promoting rhizobacteria as biofertilizers. Plant Soil 255:571-586.

Weller, D.M. 2007. Pseudomonas biocontrol agents of soil borne pathogens: looking back over 30 years. Phytopathol. 97:250-256.

Zimmer, W. and H. Bothe. 1988. The phytohormonal interactions between Azospirillum and wheat. Plant Soil 110:239-247. 